\title{
Surface Modified Electrodes Used In Cyclic Voltammetric Profiling Of Quinine An Anti-Malarial Drug.
}

\author{
Duke Orata ${ }^{*}$, Yusuf Amir ${ }^{1}$,Claire Nineza ${ }^{2}$, Damaris Mbui ${ }^{1}$, Marina Mukabi ${ }^{1}$ \\ ${ }^{1}$.Department of Chemistry University of Nairobi P.O. Box 30197-00100 Nairobi \\ ${ }^{2}$.University of Burundi, Bujumbura *Author to whom all correspondence should be addressed
}

\begin{abstract}
In this paper electrochemical profiling of quinine, an effective anti-malarial drug administered to humans, was done using primarily the very versatile electrochemical technique-cyclic voltammetry. In the electro-analysis, the main supporting electrolyte used was sulphuric acid. The surface of the working electrode was modified using electronically conducting polymer-polyanailine and a clay montmorillonite- bentonite. Quinine and metal cation $\mathrm{Cu}^{2+}, \mathrm{Co}^{2+}, \mathrm{Zn}^{2+}$ and $\mathrm{Sn}^{2+}$ were also used to modify the electrode surface.The results obtained showed that quinine oxidation /reduction potential on bare carbon graphite electrode occured at $0.495 \mathrm{~V} / 0.300 \mathrm{~V}$ and $0.015 \mathrm{~V}\left(0.25 \mathrm{M} \mathrm{H}_{2} \mathrm{SO}_{4}\right.$ supporting electrolyte). Bentonite modified electrode gave $0.434 \mathrm{~V} / 0.480 \mathrm{~V}\left(1 \mathrm{M} \mathrm{H}_{2} \mathrm{SO}_{4}\right.$ supporting electrolyte) and 0.360V/0.345V (1M HCl supporting electrolyte). A mechanistic pathway for the oxidation of quinine has also been proposed. It was also observed from the results obtained from studies on the effect of consumables such as tea, glycine and milk on quinine, that milk totally suppressed the redox process in quinine. Amino acids which are the building blocks in proteins and which is an important macromolecule in humans, does not affect significantly the redox process in quinine.

Cyclic voltammetric profiling of quinine interaction with metal cations such as $\mathrm{Cu}^{2+}, \mathrm{Co}^{2+}, \mathrm{Zn}^{2+}$ and $\mathrm{Sn}^{2+}$ and drugs such as paracetamol, acetyl salicylic acid, hydrocortisone and ferrous fumarate revealed interactions between the redox centers.
\end{abstract}

Key Words: Surface modified electrodes, cyclic voltammetry, polyaniline, bentonite and quinine

\section{Introduction:}

Quinine has been a major asset in the fight against malaria, a disease caused by a one-celled parasite known as plasmodium thought to be transmitted to humans through the bite of a female Anopheles mosquito. The four distinct plasmodia that infect humans are : P.malariae, P. ovale, P. falciparum and P. vivax.

P. vivax and P. falciparum are the most common and P.falciparum the most deadly type of malaria infection. Extensive research has been conducted in an effort to contain malaria(1-17)

In this study we applied surface derivatised electrodes to study and assess the quality of anti-malarial drug quinine electrochemically.

In the analysis the oxidation-reduction profile of the quinine was analyzed using a versatile electrochemical tool- cyclic voltammetry. In addition, cyclic voltammetry was used to study redox interaction of quinine with consumables such as tea and milk, drugs such as acetylsalicylic acid, paracetamol, iso-nicotinic acid, hydrocortisone and ferrous fumarate. Quinine interaction with metal cations is also reported.

\section{Experimental Section:}

All chemical reagents were used as received without further purification, except the monomer liquid Aniline (Aldrich 99\%) which was triply distilled until colorless liquid was obtained . It was then stored under nitrogen.

All solutions were prepared using de-ionized water. The clay montmorillonite, bentonite (sourced from Athi River Mining Company Ltd., Kenya) was purified as described by Bard(18-19). It has a mesh size ranging from 150 to $200 \mathrm{um}$, cation exchange capacity (CEC) $1.18-1.22 \mathrm{mM} / \mathrm{g}$ and a $\mathrm{pH}$ range of 8.4-9.6. The density of the bentonite is $1.25 \mathrm{~g} / \mathrm{cm} 3$ which are comparable to other clay minerals from different parts of the world (18). It has a solvent retention capacity of $22.5 \%$ and $4.8 \%$ for water and organic solvents respectively, while its moisture content is $8.5 \%$. It swells by a factor of 1.7 and 1.4 in water and organic solvents respectively

In generating the cyclic potential scans, two sets of instruments were used. These comprised of a Princeton Applied Research (PAR) model 173 pontentiostat/galvanostat, a logarithmic current converter model 369 that controlled the current, a PAR model 175 universal programmer and a PAR RE $0089 \mathrm{X}-\mathrm{Y}$ recorder. 
Electrochemical analysis of quinine:

\section{Results and Discussion}

The electrochemical response of quinine was carried out on bare carbon graphite and bentonite modified working electrode. $300 \mathrm{mg}$ of quinine was in a solution of $0.25 \mathrm{M}$ sulphuric acid. The potential was cycled from $-0.4 \mathrm{~V}$ to $0.90 \mathrm{Vat}$ a scan rate of $10 \mathrm{mV} / \mathrm{sec}$.

The resultant cyclic voltammetric response is shown in figure 1.

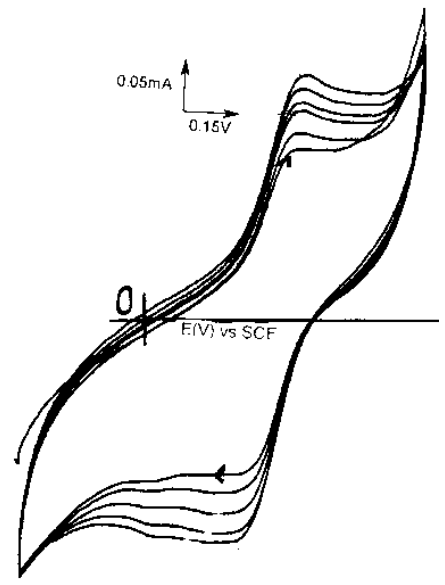

Fig. 1: Cyclic voltammetric response obtained when bare carbon working electrode potential was cycled within the potential range $-0.4 \mathrm{~V}$ to $0.90 \mathrm{~V}$ in a solution containing $300 \mathrm{mg}$ of quinine and $0.25 \mathrm{M} \mathrm{H}_{2} \mathrm{SO}_{4}$ solution

The redox process is quasi reversible with the oxidation peaks occurring at $0.495 \mathrm{~V}$ and reduction peaks occurring at $0.300 \mathrm{~V}$ and $0.015 \mathrm{~V}$ respectively. It is notable that the reductive peak consists of several peaks, suggesting the presence of several redox centers. Quinine has a pyridine ring, therefore the presence of multiple peaks is not surprising given that, the pyridine ring has methoxy functional group. Attached as a side chain is also alcohol group.The redox potential observed occur at about the same potential as that, for quinine/imine derivatives observed during electrodegradation of polyaniline, a polymer electro generated from electro polymerization of aniline. As the concentration of acid in the electrolyte media was increased, there was tremendous improvement in the redox profile of the quinine, yielding much better defined peaks (see figure 2).

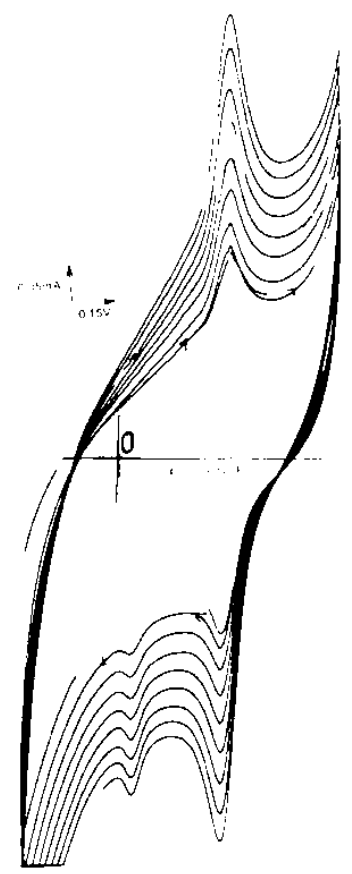

Fig. 2: Cyclic voltammetric response obtained when bare carbon working electrode potential was cycled within the potential range $-0.4 \mathrm{~V}$ to $0.90 \mathrm{~V}$ in a solution containing $300 \mathrm{mg}$ of quinine and $2 \mathrm{M} \mathrm{H}_{2} \mathrm{SO}_{4}$ solution. 
It is worth noting that, in the case of $2 \mathrm{M}$ sulphuric acid solution, the reduction peak forms two clearly defined peaks. In the case of the oxidation peak, we have a single peak at $0.4425 \mathrm{~V}$ and the reduction peaks occur at $0.4125 \mathrm{~V}$ and $0.006 \mathrm{~V}$. It is apparent from this result that, the quinine redox process is strongly $\mathrm{pH}$ dependent. We observe a negative shift in the redox potentials with increasing $\mathrm{pH}$. This observation can be attributed to the possibility of an e-c mechanism where we have electron transfer followed by a chemical reaction. In addition, the quinine/imine derivatives alluded to earlier have a strongly $\mathrm{pH}$ dependent redox process. This $\mathrm{pH}$ dependent redox activity of quinine is important given that, the $\mathrm{pH}$ is important in the gastrointestinal tract of humans. This therefore means that the gastro intestinal system $\mathrm{pH}$ can impact on the absorption of quinine given that, there is always a Donnan potential developed across the membrane .

Scan rate dependence studies yielded linear plots, as in the case of anodic peak current versus square root of scan rate (See figure 3). This suggests that, the quinine redox process is a diffusion limited process.



Fig. 3: Plot of $i_{\text {pa }}$ versus $v^{1 / 2}$ (quinine on bare carbon)

Bentonite Modified Electrode:

Similar analysis was repeated, but on a bentonite modified electrode. The objective of this experiment was to study the effect of the host matrix on the redox behavior of quinine. The electrolyte media contained $300 \mathrm{mg}$ of quinine in $1 \mathrm{M}$ sulphuric acid solution and in another set $1 \mathrm{M}$ hydrochloric acid. The potential window ranged from $-0.4 \mathrm{~V}$ to $0.90 \mathrm{~V}$. The resultant $\mathrm{CV}$ responses are shown in figures 4 and 5.

Fig. 4

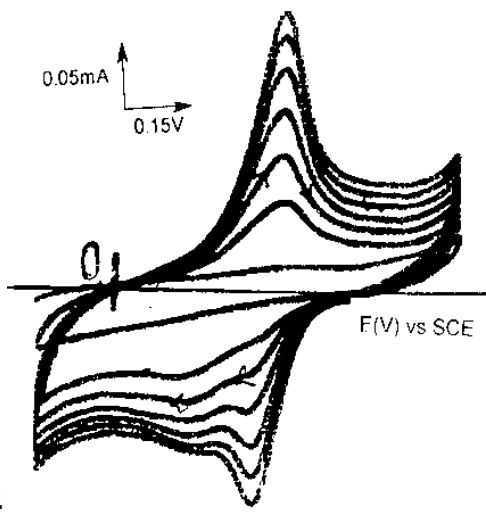

Fig. 5

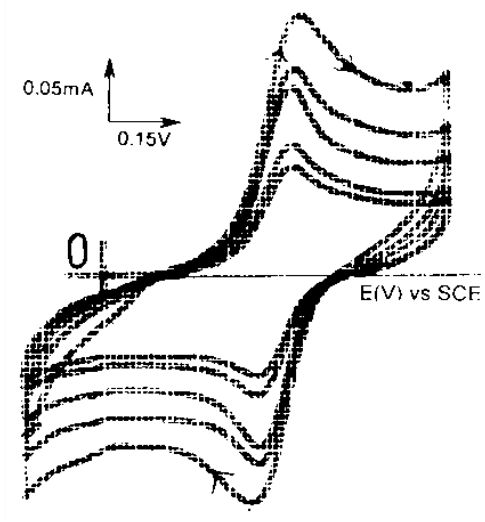

Fig. 4: Cyclic voltammogram obtained when bentonite modified carbon working electrode was cycled within the potential range $-0.4 \mathrm{~V}$ to $0.90 \mathrm{~V}$ in a solution containing $300 \mathrm{mg}$ of quinine and $1 \mathrm{M} \mathrm{H}_{2} \mathrm{SO}_{4}$

Fig. 5: Cyclic voltammogram when bentonite modified carbon working electrode was cycled within the potential range $-0.4 \mathrm{~V}$ to $0.90 \mathrm{~V}$ in a solution containing $300 \mathrm{mg}$ of quinine and $1 \mathrm{MHCl}$ 
In all the cases the cyclic voltammograms in both acid media had well defined peaks with the oxidation and reduction peaks for the sulphuric acid and hydrochloric acid occurring at $0.435 \mathrm{~V} / 0.480 \mathrm{~V}$ and $0.360 \mathrm{~V} / 0.345 \mathrm{~V}$ respectively. It is apparent from the results that the bentonite host matrix which is characterized by the presence of octahedral and tetrahedral plates (Bard et al) has probably suppressed/inhibited the follow-up chemical reaction observed in the bare carbon case. This improved redox response of quinine in the bentonite modified electrode can be attributed to the pre-concentration of the quinine molecules as a result of being trapped in the octahedral layers in the bentonite. This alignment of quinine in the clay montmorrilonite matrix decreases the overall entropy of the quinine molecules. It is also observed that, the redox potential is different. This differences can be attributed both to the nature of the host matrix and the type and size of anions in the supporting electrolyte i.e., chloride ions $\left(\mathrm{Cl}^{-}\right)$in the case of hydrochloric acid and hydrogen sulphate/sulphate ions $\left(\mathrm{HSO}_{4}{ }^{-} / \mathrm{SO}_{4}{ }^{2-}\right)$ in the case of sulphuric acid. The differences in the nature of the anions will affect their ingress profiles into the bentonite matrix subsequently affecting their redox potentials

To assess the behavior of quinine on the working electrode surface, scan rate dependence studies were conducted. A plot of anodic peak current versus square root of scan rate for quinine on bentonite modified electrode in hydrochloric acid, yielded a linear plot suggesting that the quinine is not a surface attached species and the redox process is diffusion limited (See figure 6). The fact that diffusion of quinine redox active moiety into the bentonite is the rate determining step is not surprising given that quinine is a bulky molecule.

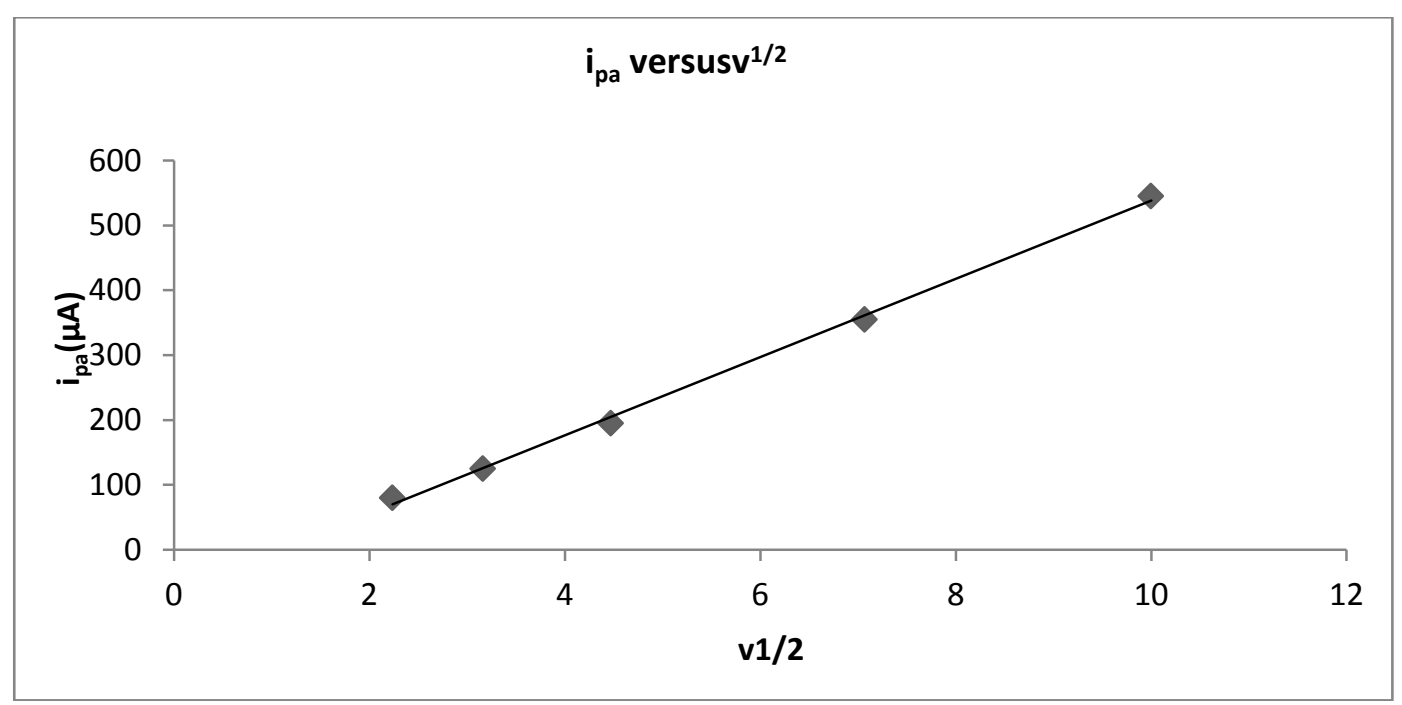

Fig. 6: $i_{\text {pa }}$ versus $v^{1 / 2}$ in the case of quinine on bentonite modified electrode in $1 \mathrm{M} \mathrm{HCl}$

The pH dependence studies show that the redox peak attributed to quinine shifts towards positive potentials as the electrolyte $\mathrm{pH}$ is decreased. See figure 7.

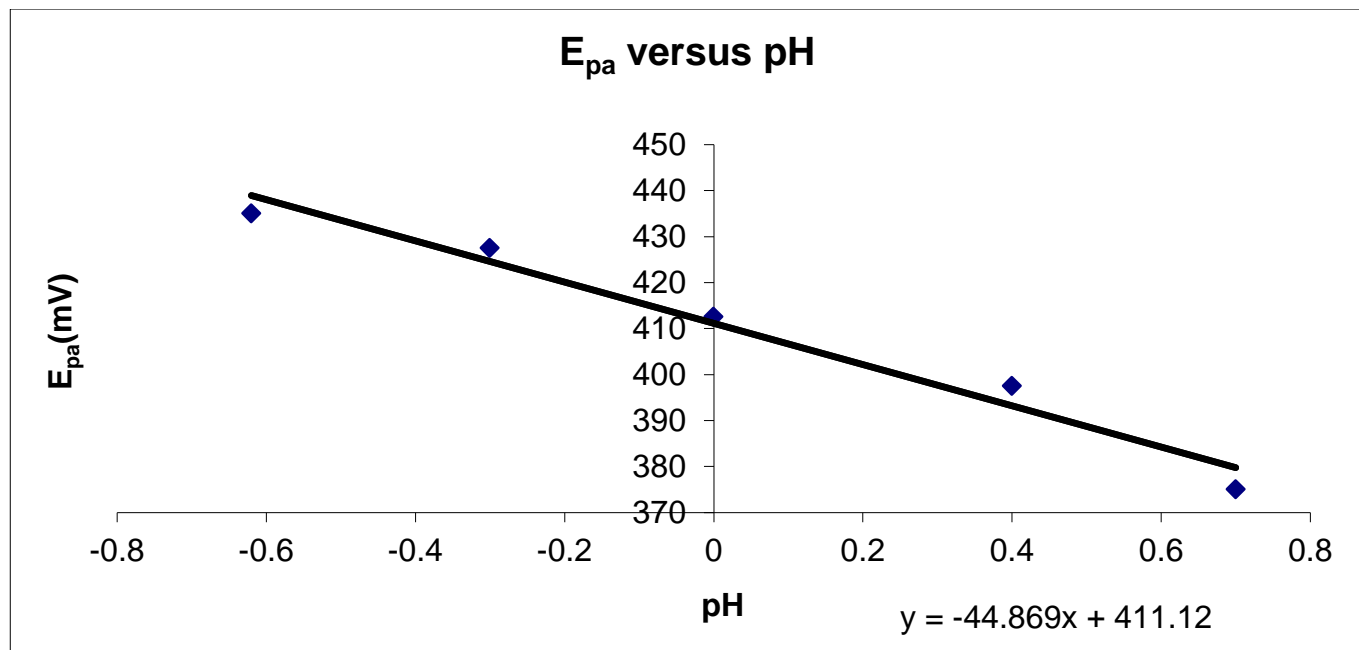

Fig. 7: Plot of $\mathrm{E}_{\mathrm{pa}}$ versus $\mathrm{pH}$ for quinine on bentonite modified electrode in $\mathrm{H2SO4}$ solutions (0.1M,0.5M,1.0M,1.5M and 2.0M). 
The oxidation potential versus $\mathrm{pH}$ curve had a slope of $-44 \mathrm{mV} / \mathrm{pH}$ unit. This suggests that, the quinine redox process is a $1 \mathrm{H}^{+} / 1 \mathrm{e}^{-}$process. This observation suggests that, the central redox activity in quinine is as a result of redox activity of the pyridine derivative in the molecule..

\section{Polyaniline Modified electrode:}

The surface of the working electrode was modified with polyaniline. The polyaniline film was electrodeposited on the electrode surface by cycling the potential of a solution containing $0.1 \mathrm{M}$ aniline in $1 \mathrm{M}$ sulphuric acid and cycling the potential from $-0.2 \mathrm{~V}$ to $0.80 \mathrm{~V}$ at a scan rate of $20 \mathrm{mV} / \mathrm{sec}$. A thin film of polyaniline, having an oxidative peak current of $2.05 \mathrm{~mA}$ on the cyclic voltammogram was used as the host matrix. the polyaniline modified electrode was then transferred to a solution containing $0.1 \mathrm{~g}$ quinine in $1 \mathrm{M}$ sulphuric acid. The resultant cyclic voltammograms are shown in figures $8 \mathrm{a}$ and $8 \mathrm{~b}$. responses are shown in figures 10a and 10b.

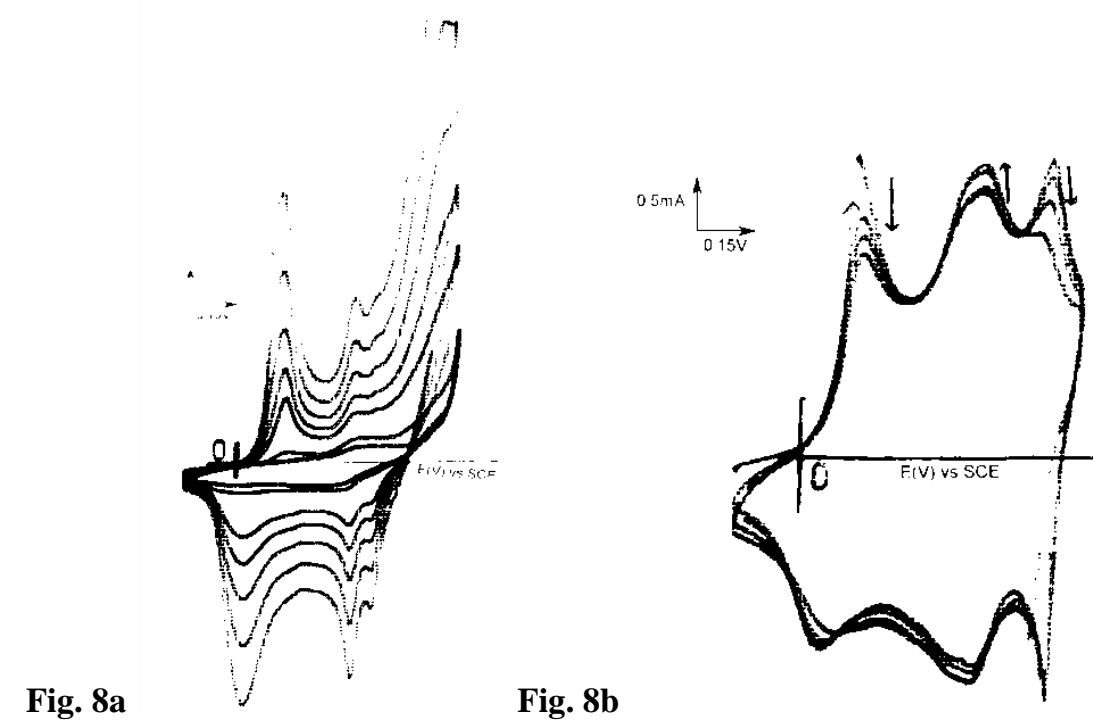

Fig. 8a: CV response of PAN electrodeposited on bare carbon graphite electrode in a solution

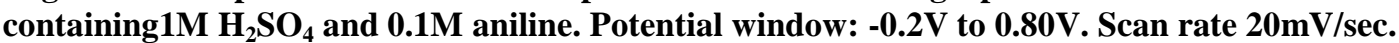

Fig. 8b: Cyclic voltammogram when polyaniline modified carbon working electrode was cycled from $0.4 \mathrm{~V}$ to $0.90 \mathrm{~V}$ in a solution containing $300 \mathrm{mg}$ of quinine and $1 \mathrm{M} \mathrm{H}_{2} \mathrm{SO}_{4}$

We observed that the oxidative peak potential for the quinine overlaps with the quinine/imine redox peaks at the potentials $0.540 \mathrm{~V} / 0.501 \mathrm{~V}$. This confirms our earlier assertion that oxidation of quinine leads to the formation of quinine/imine derivatives. It is also apparent that the oxidation potential of quinine is significantly altered positively on a polyaniline modified electrode. This is not surprising in that the orientation of quinine molecules on the polyaniline host matrix is affected by the fact that, there will be a tendency of the heterocyclic nitrogen in the quinine ring and that in the polyaniline polymeric structure to cluster together. The net effect of this is a decrease in the entropy of the quinine on the polyaniline host matrix leading to an increased oxidation potential.

\section{Quinine Modified Electrode:}

In this experiment, the surface of the carbon graphite working electrode was modified with quinine. The potential of the quinine modified electrode was cycled from $-0.4 \mathrm{~V}$ to $0.90 \mathrm{~V}$ in $1 \mathrm{M}$ sulphuric acid. The scan rate was $20 \mathrm{mV} / \mathrm{sec}$. The resultant cyclic voltammogram is shown in figure 9 . The redox activity is reversible and the rate of change of anodic peak current with time is linear. 




Fig. 9: Cyclic voltammogram when quinine modified carbon working electrode was cycled within the potential range $-0.4 \mathrm{~V}$ to $0.90 \mathrm{~V}$ in $1 \mathrm{M} \mathrm{H}_{2} \mathrm{SO}_{4}$ at a scan rate of $20 \mathrm{mV} / \mathrm{sec}$

The redox response is reproducible therefore pointing at a memory effect or factor in relation to the redox process. Such a memory effect has been observed in polymeric system such as polyaniline, where the film is stable even after nearly a million potential cycles. This property of quinine is a pointer to the prominent role of the pyridine group leading to a form of di/poly-merization of quinine involving the nitrogen group in the pyridine ring.

The deposition rate is proportional to the change in peak current since the anodic peak current is proportional to oxidative charge. This in turn can be related to the surface coverage by the equation

$\Gamma_{\mathrm{T}}=\frac{\mathrm{Q}_{\mathrm{ox}}}{\mathrm{nFA}}$

Where $\mathrm{Q}_{\mathrm{ox}}$ is the oxidative charge, $\Gamma_{\mathrm{T}}$ is the surface coverage, $\mathrm{n}$ is the number of electrons, $\mathrm{A}$ is the surface area of the electrode and $\mathrm{F}$, the Faraday constant.

The maximum oxidative charge occurred after $15 \mathrm{~min}$. This charge corresponds to the surface coverage of $8.39 \times 10^{-9} \mathrm{~mol} / \mathrm{cm}^{2}$.

This value corresponds to $0.03 \mathrm{~g}$ of quinine which based on the molecular weight of quinine gives a surface coverage of $7.62 \times 10^{-5} \mathrm{~mol} / \mathrm{cm}^{2}$. The concentration of redox active drug species deliberately attached at the working electrode surface was computed using the limiting oxidative charge for quinine. The percentage of electro active species is $0.011 \%$.

We observe that, the quinine oxidative peak potential overlaps with the quinine/imine redox peaks at $0.540 \mathrm{~V} / 0.510 \mathrm{~V}$. This is in agreement with our earlier assertion that, oxidation of quinine leads to formation of quinone derivatives. It is also apparent that, on the polyaniline host matrix, we have a significant positive potential of quinine.This implies that, the polyaniline host matrix influences the redox potential of quinine, in this case increasing its oxidation potential. This is not surprising given that, the orientation of quinine molecules in the polyaniline host matrix will probably be characterized by the tendency of the heterocyclic nitrogen in quinine aligning itself with nitrogen $\mathrm{s}$ in the polyaniline polymeric structure, leading to a decrease in the entropy leading to an increase in the oxidation potential.

\section{Proposed Mechanistic Pathway for the Oxidation of Quinine:}

We propose that the mechanistic pathway for quinine oxidation is the one shown in Scheme 1 . The oxidation (steps 1 to 6 ) shows the removal of one electron and one proton. This is in agreement with our observation where the shift in oxidation potential versus $\mathrm{pH}$ is $58 \mathrm{mV} / \mathrm{pH}$. On continued oxidation /electrode gradation, we note quinine/imine peaks reminiscent of electro-degradation of polyaniline where quinine imine derivatives were formed. We propose therefore propose that, the steps associated with this quinine oxidation process are in steps 1 to 5 . 
formed.<smiles>Cc1ccnc2ccccc12</smiles>

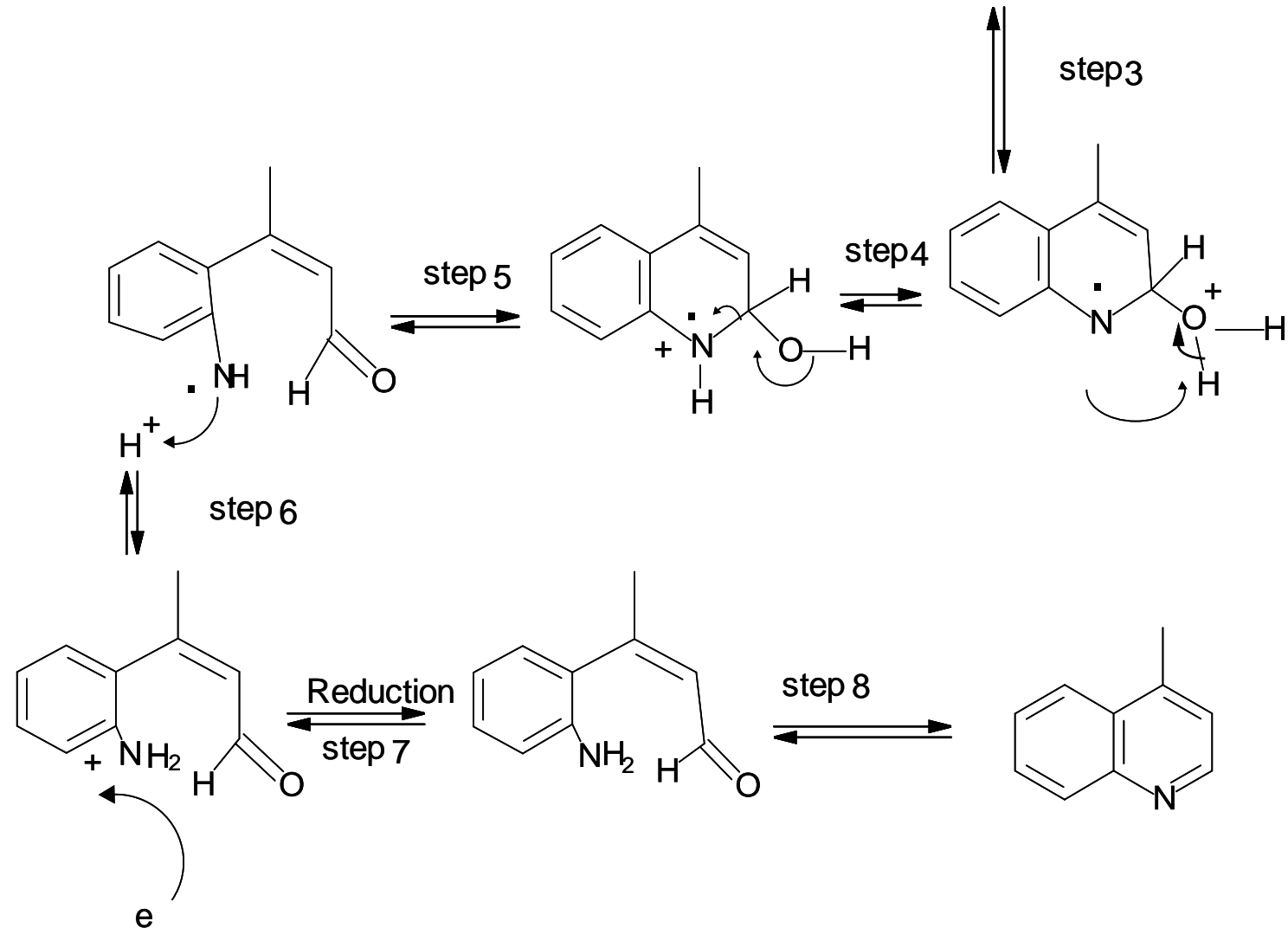

Scheme 1: Proposed mechanistic pathway for the quinine redox process

\section{Interaction of Quinine with Various Substances:}

The carbon graphite working electrode was modified with quinine as already described. The quinine modified electrode was then transferred to various electrolyte media containing 4000ppm tyrosine, 4000ppm cholesterol, 4000ppm leucine, 4000ppm iso-nicotinic acid and 4000ppm acetylsalicylic acid. The supporting electrolyte in all the cases was $1 \mathrm{M}$ sulphuric acid. The potential was cycled from $-0.2 \mathrm{~V}$ to $0.9 \mathrm{~V}$ at a scan rate of $20 \mathrm{mV} / \mathrm{sec}$. The choice of the interactive substance was based on the fact that, proteins are important in human physiology. Salicylic acid and nicotinic acid are drugs which regularly interact with the human system when deliberately ingested orally or injected into the human physiological system. The resultant cyclic voltammetric responses are shown in figures $11 \mathrm{a}$ to $11 \mathrm{~d}$. 
Fig. 11a
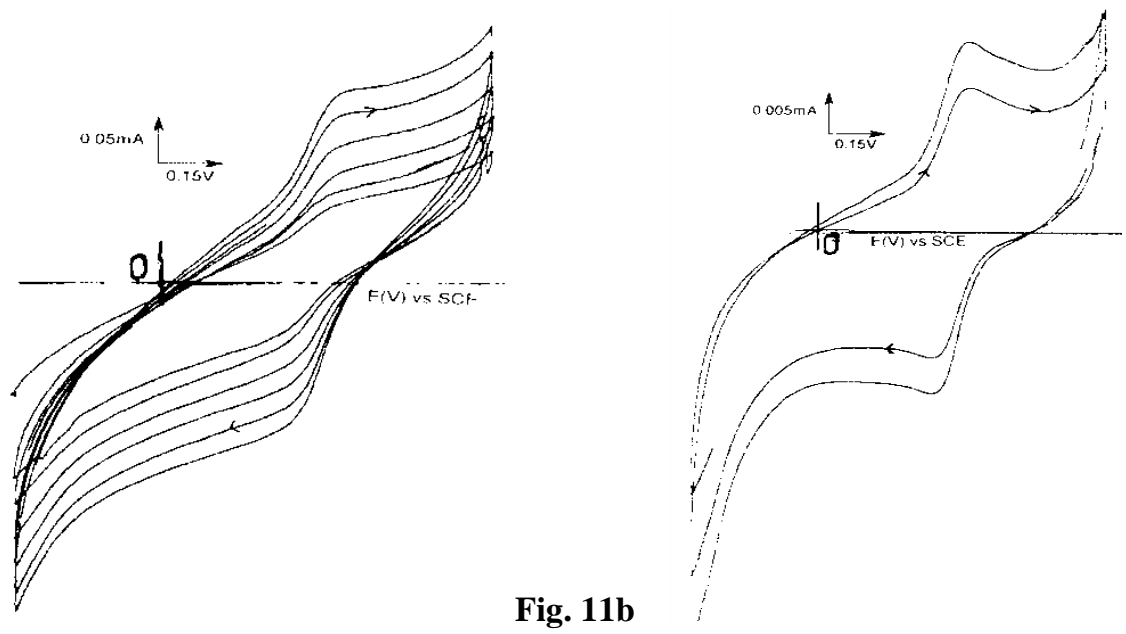

Fig. 11b

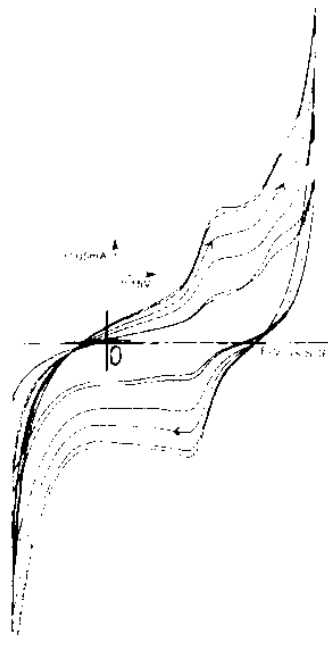

Fig. 11c

Fig. 11a, 11b, and 11c: $C V$ responses obtained when quinine modified electrode(QME) was cycled in $1 M$ $\mathrm{H}_{2} \mathrm{SO}_{4}$ and 4000ppm tyrosine; $1 \mathrm{M} \mathrm{H}_{2} \mathrm{SO}_{4}$ and 4000ppm leucine; $1 \mathrm{M} \mathrm{H}_{2} \mathrm{SO}_{4}$ and 4000ppm cholesterol.

Potential range: $-0.2 \mathrm{~V}$ to $0.9 \mathrm{~V}$. Scan rate of $20 \mathrm{mV} / \mathrm{sec}$

\section{References}

[1]. Bloland P.B., (2001), Drug Resistance in Malaria, Malaria Epidemiology Branch, Centers for Disease Control and Prevention WHO/CDS/CDS/DRS.4, 27

[2]. Blumberg P.M. and Strominger J. L., (1974), Interaction of Penicillin with the bacterial cell: Penicillin - binding proteins and penicillin - sensitive enzyme, Bact. Rev. 38, 291.

[3]. Acton N. and Roth R.J., (1992), On the conversion of dihydroartemisinic acid into artemisinin. J. Org. Chem. 57, 3610-3614.

[4]. Avery, M. A., S. Mehrotra, J. D. Bonk, J. A. Vroman, D. K. Goins, and R. Miller, (1996). Structure-activity relationships of the antimalarial agent artemisinin. 4. Effect of substitution at C-3. J. Med. Chem. 39, 2900-2906.

[5]. WHO (Roll Back Malaria), (1985).

[6]. WHO, (2001). The use of antimalarial drugs. Report of an Informal consultation. WHO/CDS/RBM33, pp:141.

[7]. Bachi, M. D., E. E., Hoos R., and Szpilman A. M., (2000). Synthesis and reactions of antimalarial bicyclic peroxides. J. Heterocycl. Chem. 37:639-646.

[8]. Bakhshi, H. B., T. Gordi, and M. Ashton. (1997). In-vitro interaction of artemisinin with intact human erythrocytes, erythrocyte ghosts, haemoglobin and carbonic anhydrase. J. Pharm. Pharmacol. 49:223-226.

[9]. Cumming, J.N., Ploypradith P. and Posner G.H. (1997), Antimalarial activity of artemisinin (qinghaosu) and related trioxanes: mechanism(s) of action. Advances in Pharmacology (San Diego) 37, 253

[10]. Graham L.P., (1997), An Introduction to Medicinal Chemistry, Oxford University Press.

[12]. Benoit-Vical F., Robert A. and Meunier B., (2000), In vitro and in vivo potentiation of artemisinin and synthetic endoperoxyde antimalarial drugs by metalloporphyrins. Antimicrob. Agents Chemother. 44, 2836-2841.

[13]. Berman, P. A., Korshin and P. A. Adams, 1997. Artemisinin enhances heme-catalysed oxidation of lipid membranes, Free Radic. Biol. Med. 22:1283-1288. 
[14]. Bunnag, D., T. Kanda, J. Karbwang, K. Thimasarn, S. Pungpak, and T. Harinasuta, (1995), Artemether-mefloquine combination in multidrug resistant falciparum malaria. Trans. R. Soc. Trop. Med. Hyg. 89:213-215.

[15]. China Cooperative Research Group on Qinghaosu and Its Derivatives as Antimalarials, (1982). Metabolism and pharmacokinetics of qinghaosu and its derivatives. J. Traditional Chinese Med. 2, 25-30.

[16]. Trape J. F, Pison M. P, Preziosi M. P, (1998), Impact of chloroquine resistance on malaria mortality. C R Acad Sci III, 321, 689697.

[17]. Triggs J.K., Mbrana H., Chambo O., Watkins E. and Curtis C.F., (1997), Resistance to pyrimethamine/ sulfadoxine in Plasmodium falciparum in 12 villages in North East Tanzania and a test of chlorproguanil/dapsone. Acta Trop., 63, 185-189.

[18]. Bard A.J. and Rudzinski W.E., (1986), Clay modified electrodes, Part VI: aluminium and silicon pillared clay modified electrodes, J.Electroanal. Chem. 199, 323-340

[19]. Bard A.J. and Villemure G., (1990), Part 9: Electrochemical studies of the electroactive fraction of adsorbed species in reduced and preadsorbed clay films, J. Electroanal. Chem. 282, 107-121. 